\title{
Biguanides and thiazolidinediones inhibit stimulated lipolysis in human adipocytes through activation of AMP-activated protein kinase
}

\author{
O. Bourron • M. Daval • I. Hainault • E. Hajduch • \\ J. M. Servant • J. F. Gautier • P. Ferré • F. Foufelle
}

Received: 17 July 2009 /Accepted: 26 November 2009/Published online: 31 December 2009

(C) Springer-Verlag 2009

\begin{abstract}
Aims/hypothesis In rodent adipocytes, activated AMPactivated protein kinase reduces the lipolytic rate. As the hypoglycaemic drugs metformin and thiazolidinediones activate this enzyme in rodents, we tested the hypothesis that in addition to their known actions they could have an anti-lipolytic effect in human adipocytes.

Methods Adipose tissue was obtained from individuals undergoing plastic surgery. Adipocytes were isolated and incubated with lipolytic agents (isoprenaline, atrial natriuretic peptide) and biguanides or thiazolidinediones. Lipolysis was quantified by the glycerol released in the medium. AMPactivated protein kinase activity and phosphorylation state were determined using standard procedures.

Results In human adipocytes, isoprenaline and atrial natriuretic peptide stimulated the lipolytic rate three- to
\end{abstract}

O. Bourron · M. Daval · I. Hainault • E. Hajduch • J. F. Gautier • P. Ferré $\cdot$ F. Foufelle $(\bowtie)$

Centre de Recherche des Cordeliers, INSERM, UMR-S 872,

15 rue de l'école de médecine,

Paris F-75006, France

e-mail: fabienne.foufelle@crc.jussieu.fr

O. Bourron • M. Daval · I. Hainault • E. Hajduch · J. F. Gautier

P. Ferré $\cdot$ F. Foufelle

Université Pierre et Marie Curie-Paris 6,

UMR-S 872 Paris, France

\section{J. F. Gautier}

Service de diabétologie et d'endocrinologie,

Groupement Hospitalier Universitaire Nord Saint-Louis, AP-HP,

Paris, France

J. M. Servant

Service de chirurgie plastique, Groupement Hospitalier

Universitaire Nord Saint-Louis, AP-HP,

Paris, France fourfold. Biguanides and thiazolidinediones activated AMPactivated protein kinase and inhibited lipolysis by $30-40 \%$, at least in part by inhibiting hormone-sensitive lipase translocation to the lipid droplet. Inhibition of AMPactivated protein kinase by compound $\mathrm{C}$ precluded this inhibitory effect on lipolysis. Stimulation of lipolysis also induced an activation of AMP-activated protein kinase concomitant with a drop in ATP concentration.

Conclusions/interpretation We show for the first time in human adipocytes that biguanides and thiazolidinediones activate AMP-activated protein kinase, thus counteracting lipolysis induced by lipolytic agents. In addition, $\beta$-agonistor ANP-stimulated lipolysis increases AMP-activated protein kinase activity. This is because of an increase in the AMP/ATP ratio, linked to activation of some of the released fatty acids into acyl-CoA. AMP-activated protein kinase activation could represent a physiological means of avoiding a deleterious drain of energy during lipolysis but could be used to restrain pharmacological release of fatty acids.

Keywords Adipocytes - AMP-activated protein kinase . Atrial natriuretic peptide $\cdot$ Biguanides $\cdot$ Hormone-sensitive lipase $\cdot$ Lipolysis $\cdot$ Non-esterified fatty acids .

Thiazolidinediones

$\begin{array}{ll}\text { Abbreviations } \\ \text { ACC } & \text { Acetyl-CoA carboxylase } \\ \text { AICAR } & \text { 5-Aminoimidazole-4-carboxamide-1- } \beta \text {-D- } \\ & \text { ribofuranoside } \\ \text { AMPK } & \text { AMP-activated protein kinase } \\ \text { ANP } & \text { Atrial natriuretic peptide } \\ \text { ATGL } & \text { Adipose triacylglycerol lipase } \\ \text { CREB } & \text { Cyclic AMP response element binding protein } \\ \text { FA } & \text { Fatty acid } \\ \text { HSL } & \text { Hormone-sensitive lipase }\end{array}$


PKA Cyclic AMP-dependent protein kinase

PKG Cyclic GMP-dependent protein kinase

PPARG Peroxisome proliferator-activated receptor gamma

\section{Introduction}

Adipose tissue is a key organ for the survival of mammals, as it allows them to store energy in the form of triacylglycerols during periods of nutritional abundance and to release it as fatty acids (FAs) through the lipolytic pathway in periods of energy shortage (e.g. fasting) or increased expenditure (e.g. physical exercise). The sequential hydrolysis of triacylglycerols to release FAs is regulated by specific enzymes. Adipose triacylglycerol lipase initiates lipolysis by specifically removing the first FA to produce a diacylglycerol, which is then hydrolysed by a hormone-sensitive lipase (HSL) and subsequently by a monocylglycerol lipase [1]. In rodents, catecholamines represent the most potent lipolytic signal acting through a cyclic AMP-dependent process and activation of cyclic AMP-dependent protein kinase (PKA) [1]. PKA then phosphorylates and modulates the activity of target proteins such as HSL and perilipin, a protein coating the lipid droplet [1]. Conversely, insulin is the most potent anti-lipolytic hormone, acting through the activation of phosphodiesterase $3 \mathrm{~B}$, which induces the degradation of cyclic AMP. In humans it has been reported that natriuretic peptides, particularly atrial natriuretic peptide (ANP), produced by the heart during exercise, could also stimulate lipolysis in adipocytes through a cyclic GMP-dependent protein kinase $(\mathrm{PKG})$ signalling pathway independently of cyclic AMP pathways [2].

It is now widely accepted that elevated concentrations of plasma FAs, as observed in obese individuals, have major implications for glucose homeostasis through the induction of insulin resistance [3, 4]. Insulin resistance can in turn lead to overt type 2 diabetes in predisposed individuals. In liver and muscles, the current hypothesis is that FA-induced insulin resistance involves intracellular FA metabolites that interfere with insulin signalling and thus with glucose utilisation [5]. Finally lipid deposition in pancreatic beta cells could also contribute through lipotoxicity to the reduction of insulin secretion and onset of type 2 diabetes [5]. Reducing lipolysis and thus circulating FA concentration is an attractive possibility for pharmacological treatment of insulin-resistant states and type 2 diabetes.

AMP-activated protein kinase (AMPK) is an $\alpha \beta \gamma$ heterotrimer complex that acts as a sensor of cellular energy status [6]. It is activated by stresses that deplete cellular ATP, inducing a concomitant rise in AMP and causing increased phosphorylation of the catalytic alpha subunit on Thr172 by an upstream kinase, the tumour suppressor serine/threonine kinase LKB1 [6]. We and others have shown in rodents that AMP-activated protein kinase is activated during the lipolytic process in adipocytes [7-11] and could contribute to restrain lipolysis [8,11-14]. Interestingly, administration of the pharmacological AMPK activator 5-aminoimidazole4-carboxamide-1- $\beta$-D-ribofuranoside (AICAR) reduces whole-body lipolysis in rodents and in humans [14, 15].

Biguanides and thiazolidinediones are widely used drugs for the treatment of type 2 diabetes [16]. The biguanide metformin decreases the high hepatic glucose output observed in type 2 diabetes, whereas thiazolidinediones such as pioglitazone or rosiglitazone increase muscle glucose uptake in response to insulin and are called insulin sensitisers. Metformin and thiazolidinediones have been reported to decrease the plasma concentrations of non-esterified fatty acids in type 2 diabetic patients [17-21] and the lipolytic rate in obese humans [22-24]. In rodent adipocytes, biguanides and thiazolidinediones are able to activate AMPK, and biguanides are able to reduce lipolysis [8, 25, 26].

In this paper, we analyse whether lipolysis, biguanides and thiazolidinediones induce AMPK activation in human adipocytes. We then study whether biguanides and thiazolidinediones can reduce lipolysis stimulated by $\beta$-agonist or ANP and whether AMPK activation is causal in reducing the lipolytic rate.

\section{Methods}

Participants Subcutaneous adipose tissue from the abdominal region was obtained from 20 normal to moderately overweight women (age $36.2 \pm 4.8$ years, BMI $24.6 \pm 2.6 \mathrm{~kg} / \mathrm{m}^{2}$ ) who were hospitalised for abdominal plastic surgery. Each patient was seen before the surgery to obtain her written consent and biological characteristics. All patients with chronic diseases (e.g. diabetes, obesity liver diseases, cancer) or treated with drugs (e.g. glucocorticoids) that could interfere with metabolism were excluded. All participants with obesity were also excluded to avoid recruiting patients with severe insulin resistance and lipolysis defects. This study was approved by the Ethics Committee of Saint Louis Hospital (Paris, France).

Adipocyte isolation and determination of fat cell number Mature adipocytes were isolated by collagenase treatment (Roche Diagnostics, Mannheim, Germany) according to Rodbell [27]. Fat cell number in the preparations was determined according to Daval et al. [8].

Short-term incubation of adipocytes and AMPK assay After isolation, adipocytes $\left(0.6 \times 10^{6}\right.$ to $1 \times 10^{6}$ cells $)$ were incubated in $\mathrm{KRB}$ (pH 7.4) supplemented with $2 \%$ (wt/vol.) $\mathrm{BSA}$ in a $95 \% \mathrm{O}_{2}, 5 \% \mathrm{CO}_{2}$ atmosphere for $30 \mathrm{~min}$. Cells were then washed three times with Hanks' balanced salt 
solution (Invitrogen, Paisley, UK) to remove BSA and then incubated in Hanks' balanced salt solution containing $5 \mathrm{mmol} / \mathrm{l}$ glucose at $37^{\circ} \mathrm{C}$ with or without the different effectors. AICAR $(500 \mu \mathrm{mol} / \mathrm{l})($ Cell Signaling Technology, Boston, MA, USA), phenformin (Sigma, St Louis, MO, USA) $(100 \mu \mathrm{mol} / \mathrm{l})$, pioglitazone $(250 \mu \mathrm{mol} / \mathrm{l})$ and rosiglitazone (250 $\mu \mathrm{mol} / \mathrm{l})$ (Alexis Biochemicals, Lausen, Switzerland) were added for $1 \mathrm{~h}$, whereas metformin $(2 \mathrm{mmol} / \mathrm{l})$ (Alexis Biochemicals) was added for $4 \mathrm{~h}$. When used, compound $\mathrm{C}$ (6-[4-(2-piperidin-1-yl-ethoxy)-phenyl]-3-pyridin-4-yl-pyrrazolo[1,5- $a$ ]pyrimidine; Calbiochem, Darmstadt, Germany) $(50 \mu \mathrm{mol} / \mathrm{l})$ and triacsin $\mathrm{C}$ (Alexis Biochemicals, Lausen, Switzerland) $(10 \mu \mathrm{mol} / \mathrm{l})$ were added to the adipocyte medium 2 and $3 \mathrm{~h}$, respectively, before addition of the effectors. Following treatment, adipocytes were disrupted in buffer A, $50 \mathrm{mmol} / \mathrm{l}$ HEPES ( $\mathrm{pH}$ 7.4), $1 \mathrm{mmol} / 1 \mathrm{EDTA}, 1 \mathrm{mmol} / 1 \mathrm{EGTA}, 10 \%$ glycerol, $50 \mathrm{mmol} / 1$ $\mathrm{NaF}, 5 \mathrm{mmol} / \mathrm{l}$ sodium pyrophosphate, $1 \mathrm{mmol} / \mathrm{l}$ dithiothreitol, $1 \mathrm{mmol} / \mathrm{l}$ phenylmethanesulfonylfluoride, $2 \mu \mathrm{g} / \mathrm{ml}$ aprotinine, $1 \mu \mathrm{g} / \mathrm{ml}$ pepstatin and $2 \mu \mathrm{g} / \mathrm{ml}$ leupeptin (Sigma Aldrich) supplemented with $1 \%$ (vol./vol.) Triton X-100. The cellular debris were pelleted by centrifugation at $4,000 \mathrm{~g}$ for $15 \mathrm{~min}$ at $4^{\circ} \mathrm{C}$, and the resulting supernatant fraction was recovered, adjusted to $10 \%$ (vol./vol.) polyethylene glycol 8000 and incubated for $45 \mathrm{~min}$ at $4^{\circ} \mathrm{C}$. Following further centrifugation $\left(18,000 \mathrm{~g}, 15 \mathrm{~min}, 4^{\circ} \mathrm{C}\right)$, the pellet of proteins was resuspended in buffer A without Triton X-100. Aliquots were used to assay AMPK activity using SAMS peptide in the presence of saturating concentrations of 5'AMP (200 $\mu \mathrm{mol} / \mathrm{l})$ as described previously [28].

Isolation of lipid droplets Lipid droplets were isolated as previously described [8]. Briefly, adipocytes were resuspended in $2 \mathrm{ml}$ of disruption buffer $(25 \mathrm{mmol} / \mathrm{l}$ TRIS- $\mathrm{HCl}$ [pH 7.4], $100 \mathrm{mmol} / \mathrm{l} \mathrm{KCl}, 1 \mathrm{mmol} / 1 \mathrm{EDTA}, 5 \mathrm{mmol} / 1$ EGTA and protease inhibitors) and disrupted by nitrogen cavitation at $5,500 \mathrm{kPa}$ for $10 \mathrm{~min}$ at $4^{\circ} \mathrm{C}$. The cavitate was collected, mixed with an equal volume of disruption buffer containing $1.08 \mathrm{~mol} / 1 \mathrm{sucrose}$, and overlaid sequentially with $2 \mathrm{ml}$ of $0.27 \mathrm{~mol} / 1$ sucrose buffer, $2 \mathrm{ml}$ of $0.135 \mathrm{~mol} / 1$ sucrose and $2 \mathrm{ml}$ of 'top' buffer ( $25 \mathrm{mmol} / \mathrm{l}$ TRIS- $\mathrm{HCl}$ [pH 7.4], $1 \mathrm{mmol} / 1$ EDTA and $1 \mathrm{mmol} / 1$ EGTA). Following centrifugation at $150,000 \mathrm{~g}$ for $90 \mathrm{~min}$, different fractions $(1.5 \mathrm{ml}$ each $)$ were collected from the top (fraction containing lipid droplets) to the bottom of the tube (cytosol, microsome and nuclei). The lipid droplets were then washed with top buffer and centrifuged at $3,500 \mathrm{~g}$ for $15 \mathrm{~min}$ at $10^{\circ} \mathrm{C}$.

Western blot analysis Western blots were performed according to Daval et al. [8]. Anti-phospho-acetyl-CoA carboxylase (ACC) and anti-cyclic AMP response element binding protein (anti-CREB) were obtained from Millipore (Billerica, MA, USA). Anti-phospho-AMPK (Thr172), anti-AMPK $\alpha_{1}$, anti-ACC, anti-phospho-HSL, anti-HSL and anti-PKA substrate antibodies were obtained from Cell Signaling Technology (New England Biolabs, Boston, USA). $\beta$-Actin antibody was provided by Sigma. The perilipin antibody was obtained from Progen (Heidelberg, Germany). The antibody against phospho-CREB (SER133) was from Upstate (Lake Placid, NY, USA) and the adipose triacylglycerol lipase (ATGL) antibody from Novus Biologicals (Littleton, CO, USA).

Lipolysis assay Isolated fat cells were treated in KRB (pH 7.4) containing $5 \mathrm{mmol} / \mathrm{l}$ glucose and $2 \%$ BSA with AMPK activators with or without compound $\mathrm{C}$ as described above. Adipocytes were then incubated at $37^{\circ} \mathrm{C}$ for $1 \mathrm{~h}$ in $2.5 \mathrm{ml}$ of KRB (pH 7.4) containing $5 \mathrm{mmol} / 1$ glucose and $4 \%$ BSA with or without $1 \mu \mathrm{mol} / 1$ isoprenaline (Sigma) or $100 \mathrm{nmol} / 1$ ANP (PolyPeptide Laboratories, Strasbourg, France) in an atmosphere of $95 \% \mathrm{O}_{2}, 5 \% \mathrm{CO}_{2}$. Subsequently, $1 \mathrm{ml}$ of the incubation medium was removed, acidified with $100 \mu \mathrm{l}$ of $30 \%$ trichloroacetic acid. The mixture was vigorously shaken and then centrifuged at $3,000 \mathrm{~g}$ for
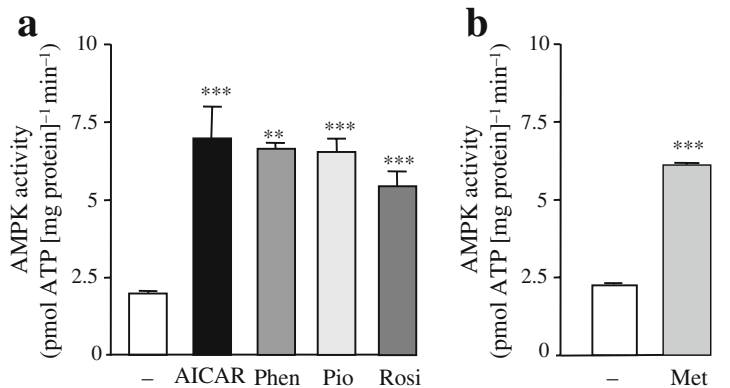

c

IB: P-AMPK Thr172

IB: $\mathrm{AMPK} \alpha$

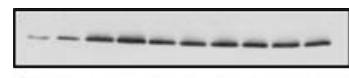

IB: P-ACC Ser80

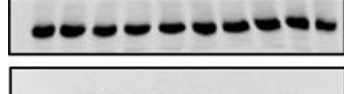

IB: ACC

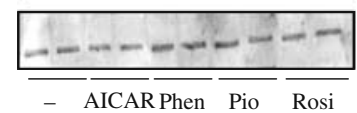

d

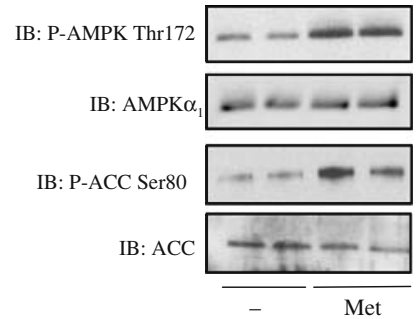

Fig. 1 Effects of AICAR, biguanides and thiazolidinediones on AMPK activity: AMPK Thr172 and ACC Ser80 phosphorylation in human adipocytes. Isolated human adipocytes were treated for $1 \mathrm{~h}$ in the presence of $500 \mu \mathrm{mol} / 1$ AICAR, $100 \mu \mathrm{mol} / 1$ phenformin (Phen), $250 \mu \mathrm{mol} / 1$ pioglitazone (Pio) and $250 \mu \mathrm{mol} / 1$ rosiglitazone (Rosi) or for $4 \mathrm{~h}$ in the presence of $2 \mathrm{mmol} / \mathrm{l}$ metformin (Met). a, b AMPK activity was measured as described in Methods. Activities shown are the means $\pm \mathrm{SE}$ from four independent experiments. ${ }^{* * *} p \leq 0.001$ compared with basal conditions. c, d Total adipocyte extracts were prepared and analysed by western blotting for phosphorylation of AMPK (Thr172) and ACC (Ser80) and for total ACC and AMPK $\alpha 1$ content. These blots are representative of at least three independent experiments 
$10 \mathrm{~min}$ at $4^{\circ} \mathrm{C}$. A volume of $700 \mu \mathrm{l}$ of supernatant fraction was collected and neutralised with $10 \%$ (wt/vol.) KOH and assayed for glycerol content (Glycerol Kit, Raisio Diagnostics SPA, Ardea, Italy).

Measurement of cellular ATP content ATP content was determined as described in Daval et al. [8].

Statistical analysis Results are expressed as the mean \pm SE. The level of significance in the difference between groups was calculated by one-way Anova analysis with corrections for multiple comparisons using Bonferroni multiple range test (Graph Pad Prism 3.0 software, Graphpad, La Jolla, CA, USA). $p<0.05$ was considered statistically significant.

\section{Results}

Biguanides and thiazolidinediones activate AMPK in human adipocytes Isolated human adipocytes were incubated for $1 \mathrm{~h}$ in the presence of $500 \mu \mathrm{mol} / 1$ AICAR, $100 \mu \mathrm{mol} / 1$ phenformin (biguanide) or two structurally different thiazolidinediones: pioglitazone and rosiglitazone (each at $250 \mu \mathrm{mol} / \mathrm{l}$ ) or for $4 \mathrm{~h}$ with $2 \mathrm{mmol} / \mathrm{l}$ metformin (Fig. 1a-d). AMPK activity (Fig. 1a-b) and Thr172 phosphorylation (Fig. 1c-d) were strongly induced in human adipocytes by AICAR, a well-known activator of AMPK. The effects of biguanides (phenformin and metformin) and thiazolidinediones (pioglitazone and rosiglitazone) on AMPK activity and phosphorylation were comparable to that observed with AICAR (Fig. 1a-d). As a consequence of AMPK activation, ACC phosphorylation on serine 80 (Ser80) was increased by AICAR and by the different drugs (Fig. 1c-d).

Biguanides and thiazolidinediones inhibit both $\beta$-adrenergicand ANP-stimulated lipolysis We then studied whether biguanides or thiazolidinediones modulate the lipolytic activity of human adipocytes (Fig. 2a-f). We first checked that basal lipolysis was not modified by biguanides or thiazolidinediones (Fig. 2a-b). Lipolysis was then stimulated by addition of a $\beta$-agonist (isoprenaline) in the culture medium of human adipocytes, pre-treated for $1 \mathrm{~h}$ with pioglitazone, rosiglitazone or phenformin or pre-treated for $4 \mathrm{~h}$ with metformin. Lipolysis, measured by the content of glycerol released in the culture medium, was stimulated three- to fourfold by isoprenaline (Fig. 2c-d). As previously reported in rodent adipocytes $[8,12,13]$, isoprenalineinduced lipolysis was inhibited by $50 \%$ in the presence of AICAR (data not shown). A similar trend was observed in adipocytes treated with phenformin, pioglitazone, rosiglitazone or metformin, with a decrease in $\beta$-adrenergic-stimulated lipolysis ranging from $50 \%$ to $30 \%$ (Fig. $2 \mathrm{c}-\mathrm{d}$ ).
As mentioned in the introduction to this paper, it has been reported that in human fat cells, lipolysis can be stimulated by atrial natriuretic peptide (ANP) through a cyclic GMP/PKG signalling pathway independent of cyclic AMP production and PKA activity [2]. In the following experiments, we tested whether biguanides and thiazolidinediones can inhibit lipolysis induced by ANP. As described above, adipocytes were treated for 1 or $4 \mathrm{~h}$ with biguanides or thiazolidinediones before activation of lipolysis by ANP. ANP stimulated
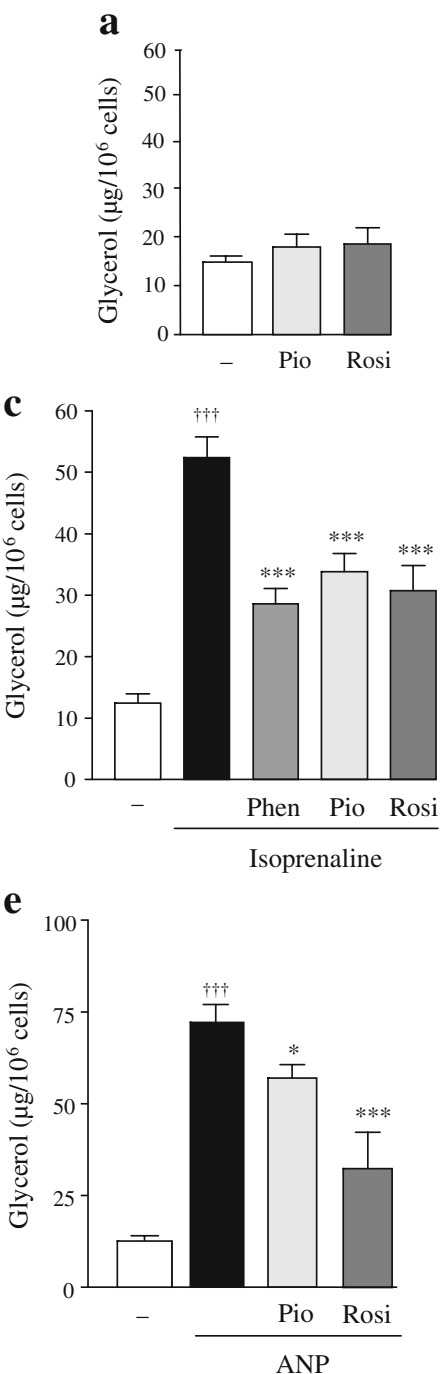

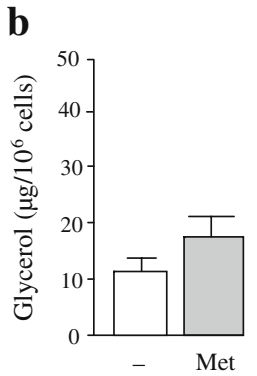

d

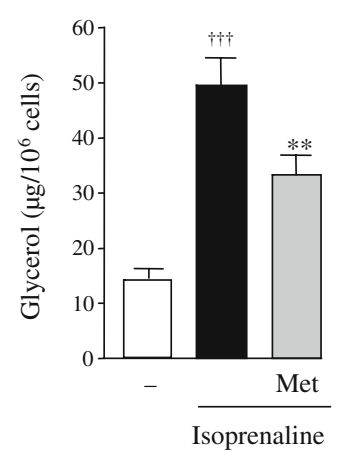

f

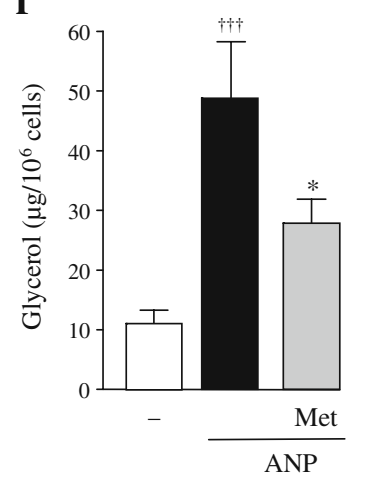

Fig. 2 Effects of biguanides and thiazolidinediones on basal, isoprenaline- and ANP-stimulated lipolysis in isolated human adipocytes. Human adipocytes were preincubated for $1 \mathrm{~h}$ in the presence of $100 \mu \mathrm{mol} / 1$ phenformin (Phen), $250 \mu \mathrm{mol} / 1$ pioglitazone (Pio) or $250 \mu \mathrm{mol} / \mathrm{l}$ rosiglitazone (Rosi) or $4 \mathrm{~h}$ in the presence of $2 \mathrm{mmol} / \mathrm{l}$ metformin (Met). Lipolysis was measured without any stimulation (a, b), or after stimulation for $1 \mathrm{~h}$ by $1 \mu \mathrm{mol} / 1$ isoprenaline $(\mathbf{c}, \mathbf{d})$ or $100 \mathrm{nmol} / 1$ ANP (e, f). Results are the means \pm SE from three independent experiments for basal conditions, five independent experiments for isoprenaline and three independent experiments for ANP. ${ }^{\dagger \dagger} p<0.001$ for comparison of isoprenaline or ANP with basal conditions. ${ }^{*} p \leq 0.05,{ }^{* *} p \leq 0.01$ and ${ }^{* * *} p \leq 0.001$ compared with conditions with isoprenaline or ANP 
lipolysis in human fat cells to the same extent as isoprenaline (Fig. 2e-f). As for isoprenaline-stimulated lipolysis, ANPstimulated lipolysis was decreased by pre-treatment with thiazolidinediones or metformin (Fig. 2e-f).

Inhibition of lipolysis by thiazolidinediones and biguanides is not linked to decreased PKA signalling One obvious explanation of the decreased lipolysis by thiazolidinediones and biguanides is that they interfere with the lipolytic signal. In order to test this possibility, we analysed downstream targets of isoprenaline-induced PKA activity, namely CREB phosphorylation on Ser133 and phospho(Ser/Thr)-PKA substrates [11]. The phosphorylation of CREB and PKA substrates was affected neither by AICAR nor by thiazolidinediones and biguanides (Fig. 3a-b), suggesting that PKA activity was not altered. The major phosphorylated PKA substrate was found at around $65 \mathrm{kDa}$, which corresponds to the molecular weight of perilipin, the predominant PKA substrate in adipocytes [11].

AMPK is activated when lipolysis is induced in human adipocytes We reported previously that in rat adipocytes AMPK activity is stimulated under conditions of increased cyclic AMP concentrations such as fasting [8]. Here we show that it is also the case in human adipocytes in which Thr172 AMPK phosphorylation is induced by treatment with isoprenaline (Fig. 4a-b). In order to decipher whether AMPK activation in adipocytes was linked to an increase in lipolysis or to an increase in cyclic AMP concentrations, we analysed the consequences of ANP on AMPK activation, as ANP induces lipolysis by a pathway independent of cyclic AMP. As shown in Fig. 4c-d, AMPK is phosphorylated in adipocytes treated for $1 \mathrm{~h}$ with ANP, suggesting that AMPK activation is linked to lipolysis induction rather than to cyclic AMP production or PKA activation. Interestingly, when AICAR, biguanides and thiazolidinediones were added on top of isoprenaline (Fig. 4a-b) or ANP (Fig. 4c-d), Thr172 AMPK phosphorylation was generally greater than with these lipolytic agents alone.

Lipolysis induced by isoprenaline or ANP was concomitant with a reduced ATP concentration in adipocytes, from $23.8 \pm 1.5 \mathrm{nmol} / 10^{6}$ cells $(n=3)$ in the basal state to 18.0 $\pm 1.0 \mathrm{nmol} / 10^{6}$ cells $(p<0.05, n=3)$ and $11.9 \pm 1.1 \mathrm{nmol} / 10^{6}$ cells $(p<0.001, n=3)$ in the presence of isoprenaline and ANP, respectively.

Inhibition of lipolysis by thiazolidinediones and biguanides is AMPK dependent Although we have shown (Figs. 1a-d and $4 \mathrm{a}-\mathrm{d}$ ) that biguanides and thiazolidinediones can activate AMPK in human adipocytes, these compounds have many other effects not related to AMPK activation. In order to establish that the decrease in the lipolytic rate induced by these drugs is dependent on AMPK activation, we inhibited AMPK with compound $\mathrm{C}$, a reversible inhibitor that is competitive with ATP [29]. Compound C was added to the culture medium $2 \mathrm{~h}$ before the addition of the AMPK activators. First, we checked whether compound $\mathrm{C}$ was able to inhibit AMPK activation and ACC phosphorylation induced by thiazolidinediones and biguanides in human adipocytes. The effects of AICAR, phenformin, metformin and thiazolidinediones on AMPK phosphorylation of Thr172 and on ACC phosphorylation of Ser80 were completely blunted in the presence of compound C (Fig. 5a-b). Having established that compound $\mathrm{C}$ blocks AMPK activation in human adipocytes, we then analysed whether biguanides and

\section{a}

IB: P-CREB Ser133

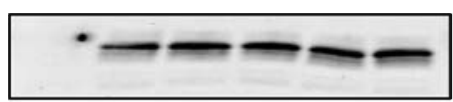

IB: CREB

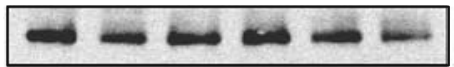

IB: P-PKA substrate

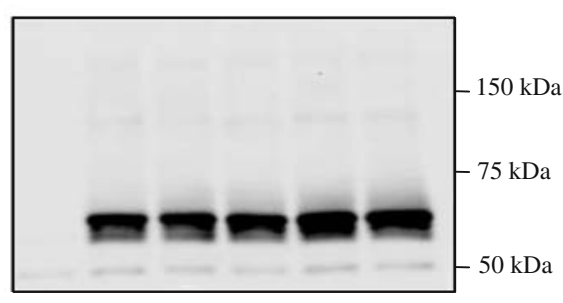

- AICAR Phen Pio Rosi

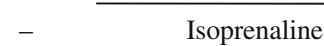

b

IB: P-CREB Ser133

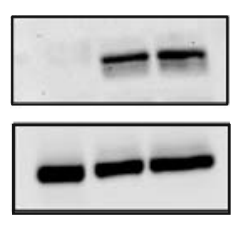

IB: CREB

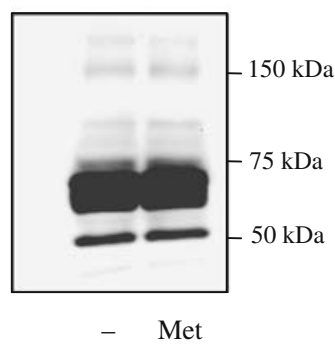

- $\overline{\text { Isoprenaline }}$

Fig. 3 Effects of AICAR, biguanides and thiazolidinediones on protein kinase A downstream targets in isolated human adipocytes. Human adipocytes were preincubated for $1 \mathrm{~h}$ in the presence of $500 \mu \mathrm{mol} / 1 \mathrm{AICAR}, 100 \mu \mathrm{mol} / 1$ phenformin (Phen), $250 \mu \mathrm{mol} / \mathrm{l}$ pioglitazone (Pio), $250 \mu \mathrm{mol} / 1$ rosiglitazone (Rosi) or $4 \mathrm{~h}$ in the presence of $2 \mathrm{mmol} / \mathrm{l}$ metformin (Met) and then incubated for another hour with $1 \mu \mathrm{mol} / 1$ isoprenaline. Total adipocytes extracts were prepared and analysed by western blotting for phosphorylation of CREB (Ser133), for total CREB content and for phosphorylation of PKA substrates. These blots are representative of two independent experiments 
a

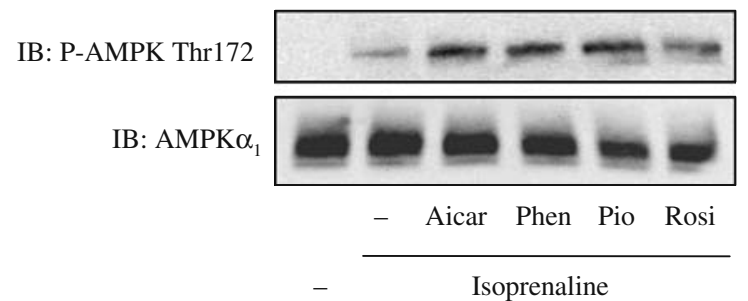

c

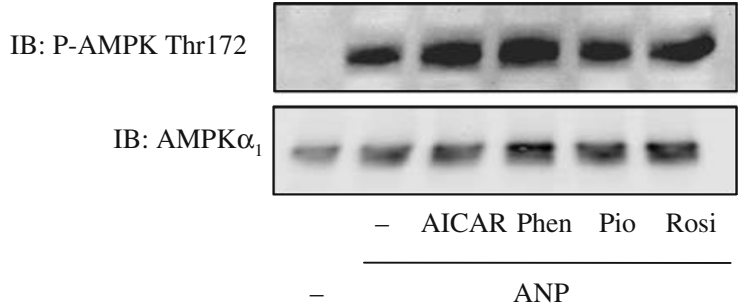

b

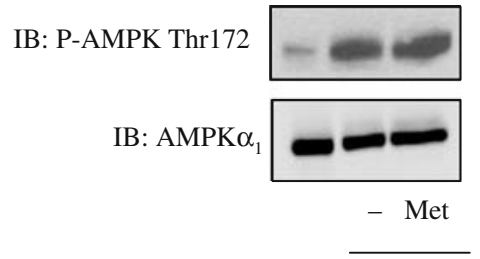

- Isoprenaline

d

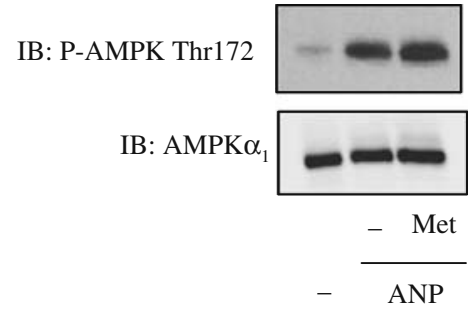

Fig. 4 Effects of AICAR, biguanides and thiazolidinediones on AMPK Thr172 phosphorylation in the presence of isoprenaline or ANP. Human adipocytes were preincubated for $1 \mathrm{~h}$ in the presence of $500 \mu \mathrm{mol} / \mathrm{l} \mathrm{AICAR}$, $100 \mu \mathrm{mol} / \mathrm{l}$ phenformin (Phen), $250 \mu \mathrm{mol} / \mathrm{l}$ pioglitazone (Pio), $250 \mu \mathrm{mol} / \mathrm{l}$ rosiglitazone (Rosi) or $4 \mathrm{~h}$ in the presence of $2 \mathrm{mmol} / \mathrm{l}$ metformin (Met) and then incubated for another hour with $1 \mu \mathrm{mol} / 1$ isoprenaline $(\mathbf{a}, \mathbf{b})$ or $100 \mathrm{nmol} / 1$ ANP (c, d). Total adipocyte extracts were prepared and analysed by western blotting for phosphorylation of AMPK (Thr172) and for total AMPK $\alpha 1$ content. These blots are representative of two independent experiments

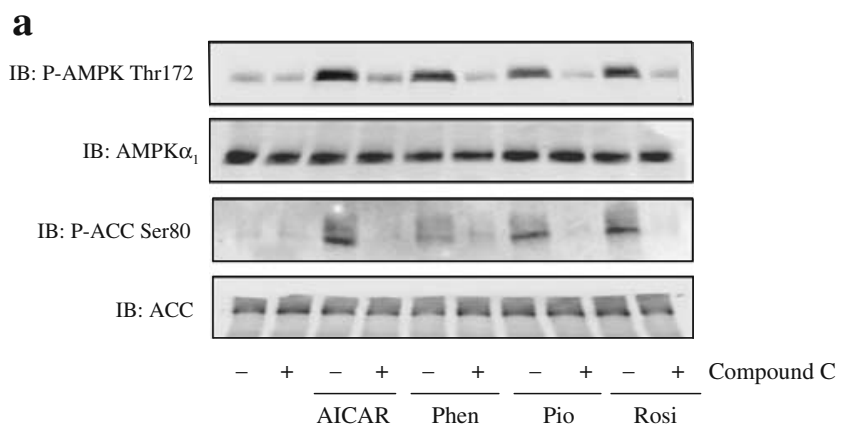

b

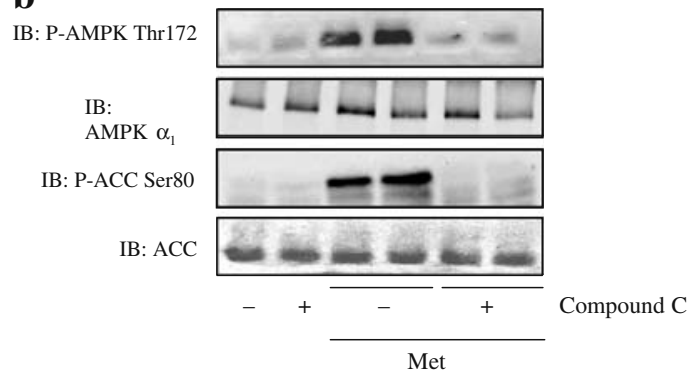

Fig. 5 Effects of AICAR, biguanides and thiazolidinediones on AMPK Thr172 and ACC Ser80 phosphorylation in the presence of compound C. Human adipocytes were preincubated in the absence or presence of compound $\mathrm{C}(50 \mu \mathrm{mol} / \mathrm{l})$ for $2 \mathrm{~h}$ and then treated for $1 \mathrm{~h}$ with $500 \mu \mathrm{mol} / 1$ AICAR, $100 \mu \mathrm{mol} / 1$ phenformin (Phen), $250 \mu \mathrm{mol} / \mathrm{l}$ pioglitazone (Pio), $250 \mu \mathrm{mol} / \mathrm{l}$ rosiglitazone (Rosi) (a) or $4 \mathrm{~h}$ with $2 \mathrm{mmol} / \mathrm{l}$ metformin (Met) (b). Total adipocyte extracts were prepared and analysed by western blotting for phosphorylation of AMPK Thr172 and ACC Ser80 and for total ACC and AMPK $\alpha_{1}$ content. These blots are representative of at least three independent experiments thiazolidinediones were still able to inhibit lipolysis in its presence. Adipocytes were sequentially treated with compound $\mathrm{C}(2 \mathrm{~h})$, then with thiazolidinediones and metformin ( 1 and $4 \mathrm{~h}$, respectively), and finally lipolysis was induced either by isoprenaline or ANP (Fig. 6a-f). Compound C itself had no effect on basal lipolysis (Fig. 6a) or on phosphorylation of CREB and PKA substrates (Fig. 6b).

As shown previously in Fig. 2c-f, thiazolidinediones and metformin reduced lipolysis induced by isoprenaline (Fig. 6c-d) or by ANP (Fig. 6e-f). The inhibitory effect of thiazolidinediones and metformin was reversed in the presence of compound C (Fig. 6c-f), demonstrating that inhibition of lipolysis by these drugs involves AMPK.

When compound $\mathrm{C}$ was added in the presence of isoprenaline, ATP concentration further dropped from $18.0 \pm 1.0 \mathrm{nmol} / 10^{6}$ cells $(n=3)$ to $6.8 \mathrm{nmol} / 10^{6}$ cells $(p<0.01, n=3)$, illustrating the importance of AMPK activation when lipolysis is stimulated in order to counteract the energy drop.

Activation of AMPK during lipolysis could be the consequence of FA re-esterification In rodent and human adipose tissue, about $20-40 \%$ of FAs released during lipolysis are re-esterified into triacylglycerols $[30,31]$. In order to be esterified, FAs are first activated into acyl-CoA by an acylCoA synthetase in an enzymatic reaction in which ATP is consumed and AMP generated. We hypothesised that, as in rodent adipocytes, AMPK activation when lipolysis is induced could be the consequence of FA re-esterification. 
Fig. 6 Effects of biguanides and thiazolidinediones on basal, isoprenaline- and ANPstimulated lipolysis in isolated human adipocytes in the presence of compound C. Human adipocytes were preincubated in the absence or presence of compound C $(50 \mu \mathrm{mol} / \mathrm{l})$ for $2 \mathrm{~h}$ and then treated for $1 \mathrm{~h}$ with $500 \mu \mathrm{mol} / 1 \mathrm{AICAR}$, $250 \mu \mathrm{mol} / \mathrm{l}$ pioglitazone (Pio), $250 \mu \mathrm{mol} / \mathrm{l}$ rosiglitazone (Rosi) or $4 \mathrm{~h}$ with $2 \mathrm{mmol} / \mathrm{l}$ metformin (Met). Lipolysis was measured in basal conditions (a) or after stimulation for $1 \mathrm{~h}$ by $1 \mu \mathrm{mol} / 1$ isoprenaline $(\mathbf{c}, \mathbf{d})$ or $100 \mathrm{nmol} / 1 \mathrm{ANP}(\mathbf{e}, \mathbf{f})$. Results are the mean \pm SE from three independent experiments for basal conditions, from five independent experiments for isoprenaline and three independent experiments for ANP.

${ }^{\dagger \dagger} p<0.001$ compared with basal conditions. ${ }^{*} p \leq 0.05,{ }^{* *} p \leq 0.01$ and ${ }^{* * * *} p \leq 0.001$ compared with conditions with isoprenaline or ANP. Human adipocytes were preincubated in the absence or presence of compound $\mathrm{C}$ $(50 \mu \mathrm{mol} / \mathrm{l})$ for $2 \mathrm{~h}$ and treated with $1 \mu \mathrm{mol} / 1$ isoprenaline for $1 \mathrm{~h}$. Adipocyte extracts were analysed by western blotting for phosphorylation of CREB

Ser133, PKA substrate and for total CREB content (b). These blots are representative of two independent experiments a

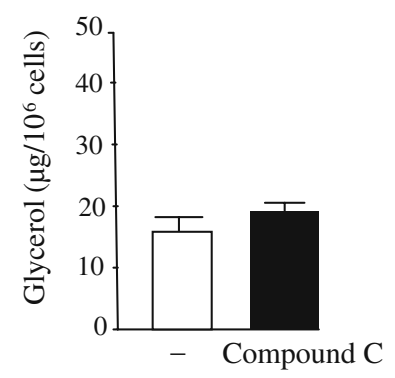

b

IB: P-CREB Ser133

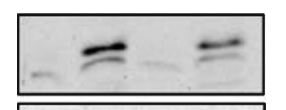

IB: CREB

IB: P-PKA substrate

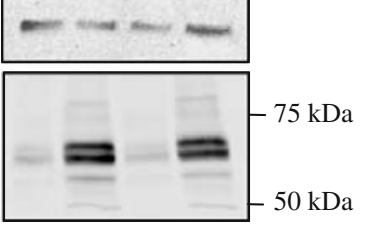

$-+\frac{-}{\text { Compound }}$ C Isoprenaline

d
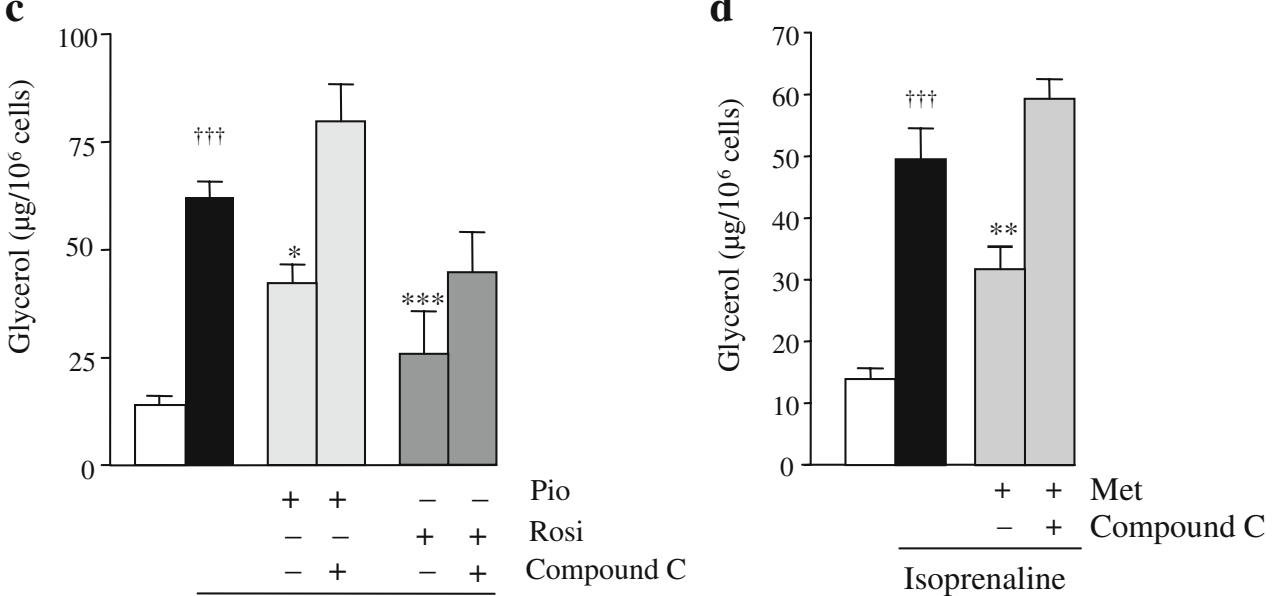

Isoprenaline
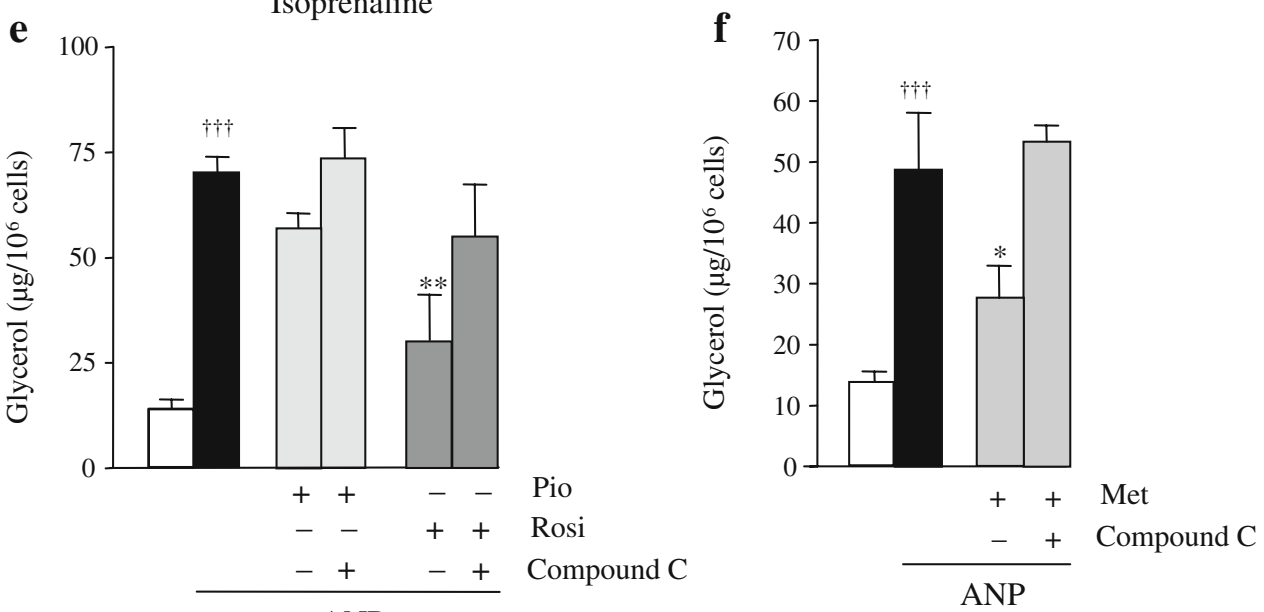

ANP

To test this hypothesis, we inhibited acyl-CoA synthetase by triacsin $\mathrm{C}$ [32] and analysed whether AMPK is still activated by lipolytic agents. We first checked that triacsin $\mathrm{C}$ does not interfere with PKA signalling, which could artificially limit isoprenaline-induced lipolysis and energy drain. As shown in Fig. 7a, triacsin C (10 $\mu \mathrm{mol} / \mathrm{l})$ during $3 \mathrm{~h}$ before induction of lipolysis by isoprenaline did not modify isoprenaline-induced phosphorylation of CREB and PKA substrates. When adipocytes were treated with triacsin $\mathrm{C}(10 \mu \mathrm{mol} / \mathrm{l})$ during $3 \mathrm{~h}$ before induction of lipolysis by isoprenaline and ANP (Fig. 7b), phosphoryla- tion of AMPK was strongly reduced, suggesting that activation of AMPK during the lipolytic process is at least partly due to FA activation.

AICAR, biguanides and thiazolidinediones reduces the ANP-induced translocation of HSL toward the lipid droplet HSL is a key enzyme controlling lipolysis in adipocytes. The activity of HSL is regulated acutely by several mechanisms, including reversible phosphorylation by a number of protein kinases and translocation from the cytosol to the surface of the lipid droplet [33]. It has been 
a

IB: P-CREB Ser133

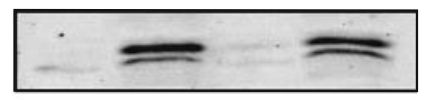

IB: CREB
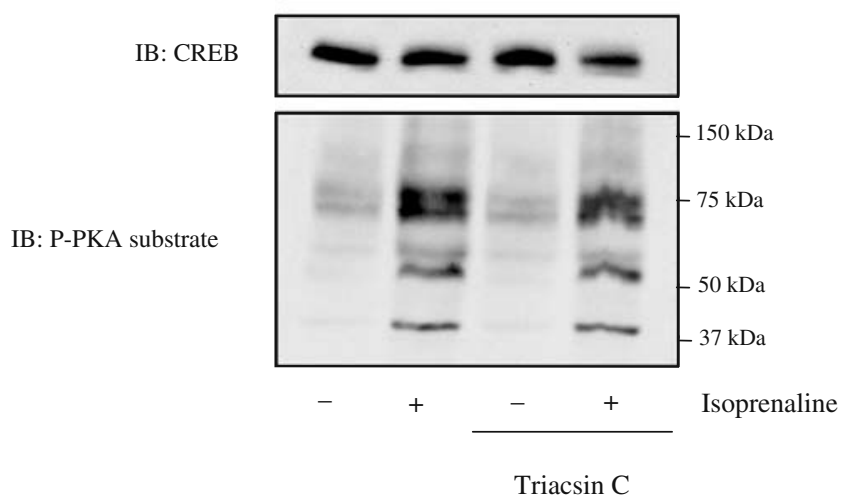

b

IB: P-AMPK Thr172

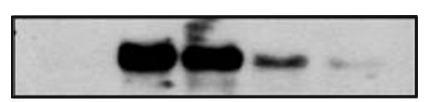

IB:

AMPK $\alpha_{1}$

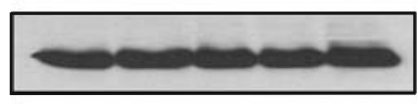

IB: P-ACC Ser80

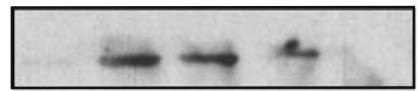

IB: ACC

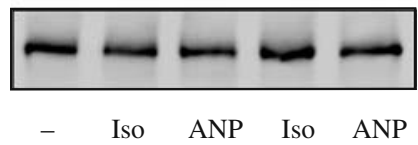

Triacsin C

Fig. 7 Effects of isoprenaline- and ANP-stimulated lipolysis on AMPK activation in human adipocytes in the absence or presence of triacsin C. Human adipocytes were preincubated for $3 \mathrm{~h}$ in the absence or presence of triacsin $C(10 \mu \mathrm{mol} / \mathrm{l})$ before addition of $1 \mu \mathrm{mol} / \mathrm{l}$ isoprenaline for $1 \mathrm{~h}$. Adipocyte lysates were analysed by western blotting for phosphorylation of CREB Ser133, for total CREB content and for phosphorylation of PKA substrates (a). Human adipocytes were preincubated for $3 \mathrm{~h}$ in the absence or presence of triacsin $\mathrm{C}$ $(10 \mu \mathrm{mol} / \mathrm{l})$ before addition of $1 \mu \mathrm{mol} / \mathrm{l}$ isoprenaline or $100 \mathrm{nmol} / \mathrm{l}$ ANP for $1 \mathrm{~h}$. Total lysates were analysed by western blotting for phosphorylation of AMPK Thr172 or ACC Ser80 and total ACC and AMPK $\alpha_{1}$ content (b). These blots are representative of two independent experiments

previously reported that the phosphorylation of rodent HSL on Ser565 has no effect on HSL activity per se but abolishes the activating phosphorylation on the adjacent Ser563 [34], thus finally decreasing HSL activity.

We have shown previously in rodent adipocytes that activation of AMPK phosphorylates HSL and impairs its translocation to the lipid droplet [8]. We have analysed here the effects of AMPK stimulation by ANP alone or ANP in the presence of AICAR, biguanides or thiazolidinediones on HSL phosphorylation and translocation to the lipid droplet (Fig. 8a-e). Treatment of adipocytes with ANP alone induces a phosphorylation of Ser554, the human equivalent of rodent Ser565 [35, 36] (Fig. 8a-b) and a translocation of HSL from the cytoplasm to the lipid droplet
(Fig. 8c-e). Interestingly, when AICAR, biguanides and thiazolidinediones are added together with ANP, phosphorylation of HSL Ser554 is more marked, and this is probably related to the higher AMPK activation (see Fig. 4a-d). This is concomitant with a reduced translocation of HSL from the cytoplasm to the lipid droplet.

\section{Discussion}

In the present work, we show for the first time that in human adipocytes activation of AMPK is able to reduce lipolysis and that drugs used as hypoglycaemic agents, biguanides and thiazolidinediones, are able to counteract lipolysis through the activation of AMPK and decreased HSL translocation to the lipid droplet. In addition, $\beta$-agonist- or ANP-stimulated lipolysis increases AMPK activity. This is probably due to a decrease in ATP and increase in AMP, linked to activation of some of the hydrolysed fatty acids into acyl-CoA rather than through an effect based on cyclic AMP generation and PKA activity.

The lipolytic process in humans is of utmost importance for metabolic homeostasis during periods of fasting and during exercise. In addition, an overflow of FAs in plasma together with a reduced tissue oxidation is a major factor in the development of abnormalities such as insulin resistance and type 2 diabetes observed in overweight individuals. Widely used hypoglycaemic drugs, thiazolidinediones and metformin, are known to reduce the concentration of plasma FAs. It is generally assumed that thiazolidinediones act through the activation of peroxisome proliferatoractivated receptor gamma (PPARG), which then modulates a cluster of genes, resulting in the channelling of FAs towards adipose tissue rather than to muscle and liver, thus reducing overall lipotoxicity and improving insulin sensitivity [37]. Interestingly, an activation of AMPK by thiazolidinediones independently of PPARG has been described in in-vitro experiments $[38,39]$ as well as an in-vivo activation of adipose tissue AMPK in rodents after thiazolidinedione treatment $[25,26]$. The mechanism by which metformin lowers plasma FAs can be related to the finding that, by activating AMPK in the liver [29], it reduces the lipogenic pathway and activates fatty acid oxidation.

We propose here a new hypothesis in order to explain how these hypoglycaemic drugs reduce plasma nonesterified fatty acids in humans. They could restrain lipolysis in adipocytes by a pathway involving AMPK. Indeed, they both induce an activation of AMPK, as shown by the increased AMPK Thr172 phosphorylation, and phosphorylation of ACC, a target of AMPK. In addition, their anti-lipolytic effect is antagonised by compound $\mathrm{C}$, an inhibitor of AMPK. The present results are supported by 
a

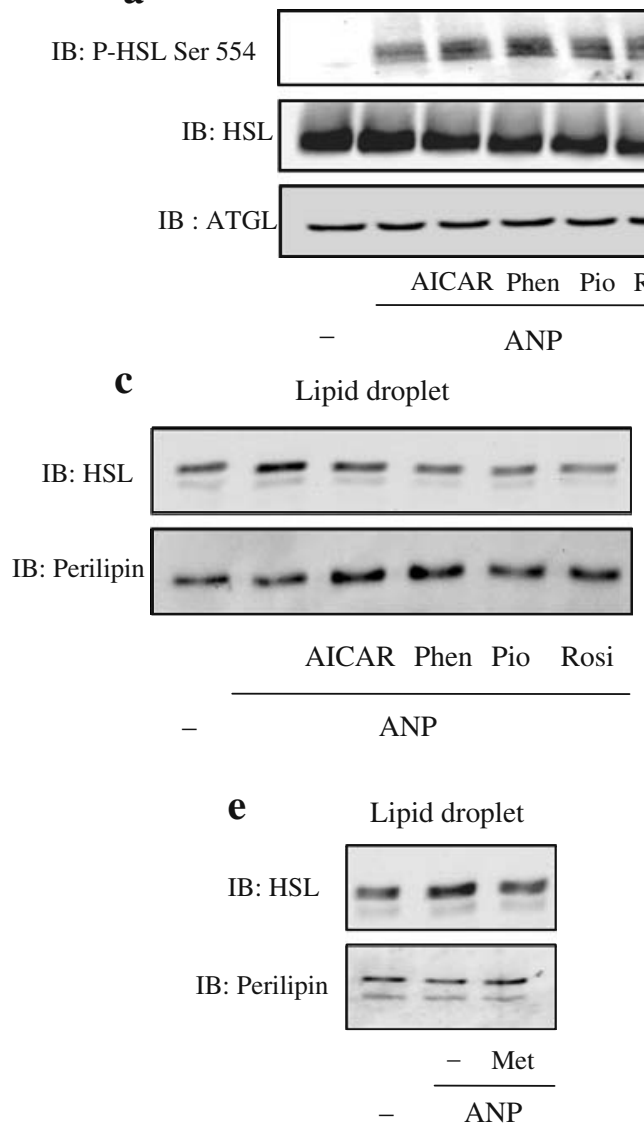

Fig. 8 Effects of AICAR, biguanides and thiazolidinediones on HSL phosphorylation and translocation in the presence of ANP. Human adipocytes were preincubated for $1 \mathrm{~h}$ in the presence of $500 \mu \mathrm{mol} / 1$ AICAR, $100 \mu \mathrm{mol} / \mathrm{l}$ phenformin (Phen), $250 \mu \mathrm{mol} / 1$ pioglitazone (Pio), $250 \mu \mathrm{mol} / 1$ rosiglitazone (Rosi) or $4 \mathrm{~h}$ with $2 \mathrm{mmol} / 1 \mathrm{metformin}$ (Met) then $100 \mathrm{nmol} / 1 \mathrm{ANP}$ was added for $1 \mathrm{~h}$. Adipocyte lysates were prepared and analysed by western blotting for phosphorylation of HSL Ser554 and for total HSL and ATGL content $(\mathbf{a}, \mathbf{b})$. These blots are representative of two independent experiments. Human adipocytes were preincubated for

results showing an anti-lipolytic effect of both metformin and the related biguanide phenformin in rodent adipocytes [8, 40], attributed for the latter drug to an activation of AMPK. Moreover, in humans, a perfusion of metformin in microdialysis experiments has an anti-lipolytic effect [22, 41].

Nevertheless, one must be extremely cautious when extrapolating in-vitro studies to the in-vivo situation. Although in the range of concentrations used in most in-vitro studies establishing their role in cellular metabolism [29, 38, 39, 42], we have used here drug concentrations well above plasma circulating concentrations of treated patients. For instance, the concentration for $1 \mathrm{~h}$ incubation with thiazolidinediones and $4 \mathrm{~h}$ with metformin corresponds approximately to a 10 - to 15 -fold higher exposure (concentration $\times$ time) than in patients in one day having the usual treatment $[43,44]$.

In rodent adipocytes, the pro- or anti-lipolytic role of AMPK is a disputed issue. It was originally proposed $[12,13]$ b

IB: P-HSL Ser 554

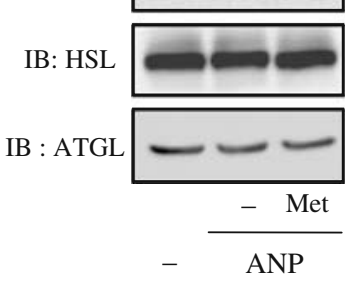

d

Cytoplasm
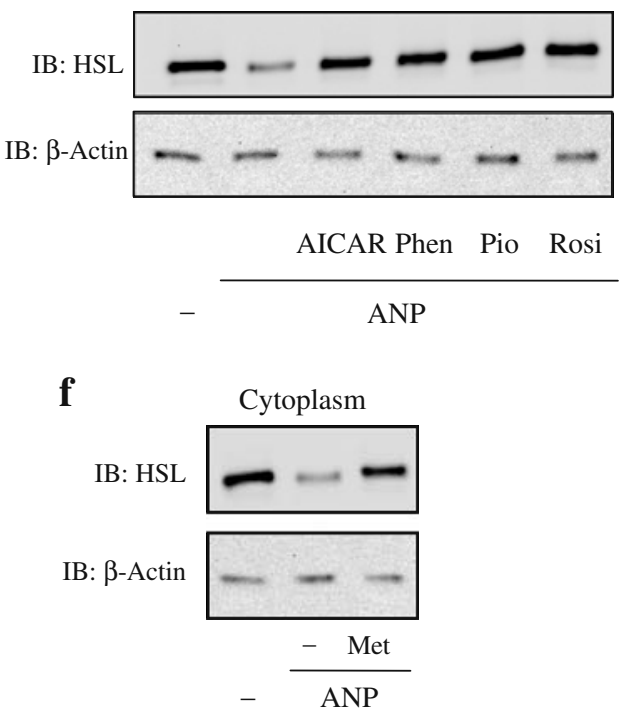

$1 \mathrm{~h}$ in the presence of $500 \mu \mathrm{mol} / 1 \mathrm{AICAR}, 100 \mu \mathrm{mol} / 1$ phenformin (Phen), $250 \mu \mathrm{mol} / \mathrm{l}$ pioglitazone (Pio), $250 \mu \mathrm{mol} / 1$ rosiglitazone (Rosi) or $4 \mathrm{~h}$ with $2 \mathrm{mmol} / 1$ metformin (Met), then $100 \mathrm{nmol} / 1 \mathrm{ANP}$ was added for $10 \mathrm{~min}$. Lipid droplets and cytosol fractions were isolated as described in Methods. Using electrophoresis, $2 \mu \mathrm{g}$ of proteins from the lipid droplet fraction and $2 \mu \mathrm{g}$ of cytosolic proteins were separated and analysed for HSL, perilipin and $\beta$-actin levels using specific antibodies $(\mathbf{c}, \mathbf{e})$

that AICAR-induced AMPK activity could reduce the lipolytic rate of rodent adipocytes. However, some studies have described a pro-lipolytic role for AMPK [9, 10], or an absence of effect [45]. We have demonstrated [8] by manipulating AMPK activity using dominant positive and negative forms of the kinase that AMPK is inhibitory in mature adipocytes. More recent studies have confirmed that AMPK activation inhibits the lipolytic pathway in rodent adipocytes [11, 14].

Concerning the mechanism by which AMPK could restrain lipolysis, an effect of AMPK on HSL activation has been described in rodent adipocytes [8, 12, 14]. AMPK phosphorylates Serine 565 of HSL, potentially precluding phosphorylation of other serine residues crucial for activation of the enzyme [46]. HSL translocation to the lipid droplet is also an important activatory mechanism [47, 48] and we have shown in rodent adipocytes a decreased 
translocation of HSL to the lipid droplet when AMPK is activated [8]. We describe here a similar phenomenon in human adipocytes when AMPK is activated by AICAR, biguanides and thiazolidinediones. Obviously this does not preclude the idea that in addition to HSL other targets are also involved in the effects of AMPK: for instance, perilipin or ATGL. The fact that lipolytic agent-induced HSL translocation is one of the targets of AMPK could explain: (1) why there is no major effect of the drugs on basal lipolysis; and (2) why this mechanism works on both isoprenaline- and ANP-induced lipolysis, because, despite different signalling, the actions of these two factors converge towards HSL translocation.

An important aspect of the present study is the fact that lipolysis itself induces an activation of AMPK in human adipocytes, whatever the lipolytic signal, $\beta$-agonists or ANP. In rodents there is also a general consensus to describe an activation of AMPK in adipose tissue following induction of lipolysis [7-11]. Although lipolysis per se does not require energy, the lipolytic process is concomitant with decreased ATP concentrations in rodent adipocytes [11, 49]. We show here that it is also the case in human adipocytes, and this can explain AMPK activation. AMPK activation when lipolysis is stimulated could contribute to the preservation of energy in the adipocytes by restraining the lipolytic process. It is interesting to note that when AMPK activity is inhibited by compound C, the decreased ATP concentration seen in the presence of a lipolysis activator is much more marked (the present study). As proposed by Gauthier et al. [11], AMPK could be viewed as a rheostat, the degree of its activation being related to the rate of lipolysis in order to protect the adipocyte from further energy drain. In rodents, it has been suggested that the reesterification process of part of the hydrolysed FAs that requires energy for acyl-CoA synthesis could explain the energy drain concomitant with lipolysis [11]. This scheme could also be the case in human adipocytes, as: (1) AMPK is activated whatever the lipolytic signal ( $\beta$-agonists or ANP, which act through different effectors (respectively cyclic AMP/PKA and cyclic GMP/PKG)); (2) AMPK activation disappears when acyl-CoA synthesis is precluded by triacsin $\mathrm{C}$.

ANP was proposed as part of an homeostatic loop acting in conjunction with the sympathetic nervous system in order to provide energy in stressed situations such as exercise [2]. During exercise, ANP is released from the heart and contributes together with the sympathetic nervous system to lipid mobilisation by adipose tissue. In humans, ANP could then contribute to exercise-induced lipolysis. We show here that under conditions of ANP-induced lipolysis, AMPK is also activated, demonstrating that AMPK activation is a general process when lipolysis is induced in adipose tissue. In humans, there are only a few studies addressing the question of AMPK activation by exercise in adipose tissue. AMPK Thr172 phosphorylation was found to be increased in the subcutaneous adipose tissue of individuals exercising for $90 \mathrm{~min}$ at $60 \% \dot{V} \mathrm{O}_{2 \max }$, inducing an increased plasma fatty acid concentration [45] whereas no change was found for AMPK activity in the study of Kristensen et al. [50] for an exercise of similar intensity but for a shorter period (40 to $60 \mathrm{~min}$ ) and for which plasma FA concentrations were not reported. Clearly this must be further documented.

In conclusion, knowing the general role of AMPK in cell biology, our studies suggest that in human adipocytes, AMPK activation is a key process for maintaining energy homeostasis when lipolysis is activated. Diverting this process through specific activators of AMPK could be an interesting means of reducing plasma FA availability and hence improving insulin sensitivity.

Acknowledgements This work was supported by grants from INSERM, Fondation pour la Recherche Médicale and by the EXGENESIS Integrated Project Grant LSHM-CT-2004-005272, funded by the European Commission. O. Bourron is the recipient of a doctoral grant from INSERM.

Duality of interest The authors declare that there is no duality of interest associated with this manuscript.

\section{References}

1. Duncan RE, Ahmadian M, Jaworski K, Sarkadi-Nagy E, Sul HS (2007) Regulation of lipolysis in adipocytes. Annu Rev Nutr 27:79-101

2. Lafontan M, Moro C, Berlan M, Crampes F, Sengenes C, Galitzky J (2008) Control of lipolysis by natriuretic peptides and cyclic GMP. Trends Endocrinol Metab 19:130-137

3. Boden G (1997) Role of fatty acids in the pathogenesis of insulin resistance and NIDDM. Diabetes 46:3-10

4. Bergman RN, Ader M (2000) Free fatty acids and pathogenesis of type 2 diabetes mellitus. Trends Endocrinol Metab 11:351-356

5. Boden G, Shulman GI (2002) Free fatty acids in obesity and type 2 diabetes: defining their role in the development of insulin resistance and beta-cell dysfunction. Eur J Clin Invest 32(Suppl 3):14-23

6. Kahn BB, Alquier T, Carling D, Hardie DG (2005) AMPactivated protein kinase: ancient energy gauge provides clues to modern understanding of metabolism. Cell Metab 1:15-25

7. Moule SK, Denton RM (1998) The activation of p38 MAPK by the beta-adrenergic agonist isoproterenol in rat epididymal fat cells. FEBS Lett 439:287-290

8. Daval M, Diot-Dupuy F, Bazin R et al (2005) Anti-lipolytic action of AMP-activated protein kinase in rodent adipocytes. J Biol Chem 280:25250-25257

9. Koh HJ, Hirshman MF, He $\mathrm{H}$ et al (2007) Adrenaline is a critical mediator of acute exercise-induced AMP-activated protein kinase activation in adipocytes. Biochem J 403:473-481

10. Yin W, Mu J, Birnbaum MJ (2003) Role of AMP-activated protein kinase in cyclic AMP-dependent lipolysis in 3T3-L1 adipocytes. J Biol Chem 278:43074-43080

11. Gauthier MS, Miyoshi H, Souza SC et al (2008) AMP-activated protein kinase is activated as a consequence of lipolysis in the 
adipocyte: potential mechanism and physiological relevance. J Biol Chem 283:16514-16524

12. Sullivan JE, Brocklehurst KJ, Marley AE, Carey F, Carling D, Beri RK (1994) Inhibition of lipolysis and lipogenesis in isolated rat adipocytes with AICAR, a cell-permeable activator of AMPactivated protein kinase. FEBS Lett 353:33-36

13. Corton JM, Gillespie JG, Hawley SA, Hardie DG (1995) 5-Aminoimidazole-4-carboxamide ribonucleoside. A specific method for activating AMP-activated protein kinase in intact cells? Eur J Biochem 229:558-565

14. Anthony NM, Gaidhu MP, Ceddia RB (2009) Regulation of visceral and subcutaneous adipocyte lipolysis by acute AICARinduced AMPK activation. Obesity (Silver Spring) 17:1312-1317

15. Boon H, Bosselaar M, Praet SF et al (2008) Intravenous AICAR administration reduces hepatic glucose output and inhibits whole body lipolysis in type 2 diabetic patients. Diabetologia 51:1893-1900

16. Krentz AJ, Bailey CJ (2005) Oral antidiabetic agents: current role in type 2 diabetes mellitus. Drugs 65:385-411

17. Abbasi F, Carantoni M, Chen YD, Reaven GM (1998) Further evidence for a central role of adipose tissue in the antihyperglycemic effect of metformin. Diabetes Care 21:1301-1305

18. Perriello G, Misericordia P, Volpi E et al (1994) Acute antihyperglycemic mechanisms of metformin in NIDDM. Evidence for suppression of lipid oxidation and hepatic glucose production. Diabetes 43:920-928

19. Riccio A, del Prato S, Vigili de Kreutzenberg S, Tiengo A (1991) Glucose and lipid metabolism in non-insulin-dependent diabetes. Effect of metformin. Diabetes Metab 17:180-184

20. Miles JM, Wooldridge D, Grellner WJ et al (2003) Nocturnal and postprandial free fatty acid kinetics in normal and type 2 diabetic subjects: effects of insulin sensitization therapy. Diabetes 52:675-681

21. Racette SB, Davis AO, McGill JB, Klein S (2002) Thiazolidinediones enhance insulin-mediated suppression of fatty acid flux in type 2 diabetes mellitus. Metabolism 51:169-174

22. Flechtner-Mors M, Ditschuneit HH, Jenkinson CP, Alt A, Adler G (1999) Metformin inhibits catecholamine-stimulated lipolysis in obese, hyperinsulinemic, hypertensive subjects in subcutaneous adipose tissue: an in situ microdialysis study. Diabet Med 16:1000-1006

23. McTernan PG, Harte AL, Anderson LA et al (2002) Insulin and rosiglitazone regulation of lipolysis and lipogenesis in human adipose tissue in vitro. Diabetes 51:1493-1498

24. Souza SC, Yamamoto MT, Franciosa MD, Lien P, Greenberg AS (1998) BRL 49653 blocks the lipolytic actions of tumor necrosis factor-alpha: a potential new insulin-sensitizing mechanism for thiazolidinediones. Diabetes 47:691-695

25. Saha AK, Avilucea PR, Ye JM, Assifi MM, Kraegen EW, Ruderman NB (2004) Pioglitazone treatment activates AMPactivated protein kinase in rat liver and adipose tissue in vivo. Biochem Biophys Res Commun 314:580-585

26. Ye JM, Dzamko N, Hoy AJ, Iglesias MA, Kemp B, Kraegen E (2006) Rosiglitazone treatment enhances acute AMP-activated protein kinase-mediated muscle and adipose tissue glucose uptake in high-fat-fed rats. Diabetes 55:2797-2804

27. Rodbell M (1964) Metabolism of isolated fat cells. I. Effects of hormones on glucose metabolism and lipolysis. J Biol Chem 239:375-380

28. Foretz M, Carling D, Guichard C, Ferre P, Foufelle F (1998) AMP-activated protein kinase inhibits the glucose-activated expression of fatty acid synthase gene in rat hepatocytes. J Biol Chem 273:14767-14771

29. Zhou G, Myers R, Li Y et al (2001) Role of AMP-activated protein kinase in mechanism of metformin action. J Clin Invest 108:1167-1174

30. Vaughan M (1962) The production and release of glycerol by adipose tissue incubated in vitro. J Biol Chem 237:3354-3358
31. Hammond VA, Johnston DG (1987) Substrate cycling between triglyceride and fatty acid in human adipocytes. Metabolism 36:308-313

32. Tomoda H, Igarashi K, Omura S (1987) Inhibition of acyl-CoA synthetase by triacsins. Biochim Biophys Acta 921:595-598

33. Yeaman SJ (2004) Hormone-sensitive lipase - new roles for an old enzyme. Biochem J 379:11-22

34. Garton AJ, Yeaman SJ (1990) Identification and role of the basal phosphorylation site on hormone-sensitive lipase. Eur J Biochem 191:245-250

35. Roepstorff C, Thiele M, Hillig T et al (2006) Higher skeletal muscle alpha2AMPK activation and lower energy charge and fat oxidation in men than in women during submaximal exercise. J Physiol 574:125-138

36. Lafontan M, Langin D (2009) Lipolysis and lipid mobilization in human adipose tissue. Prog Lipid Res 48:275-297

37. Ferre P (2004) The biology of peroxisome proliferator-activated receptors: relationship with lipid metabolism and insulin sensitivity. Diabetes 53(Suppl 1):S43-S50

38. Fryer LG, Parbu-Patel A, Carling D (2002) The anti-diabetic drugs rosiglitazone and metformin stimulate AMP-activated protein kinase through distinct signaling pathways. J Biol Chem 277:25226-25232

39. LeBrasseur NK, Kelly M, Tsao TS et al (2006) Thiazolidinediones can rapidly activate AMP-activated protein kinase in mammalian tissues. Am J Physiol Endocrinol Metab 291:E175-E181

40. Zhang T, He J, Xu C et al (2009) Mechanisms of metformin inhibiting lipolytic response to isoproterenol in primary rat adipocytes. J Mol Endocrinol 42:57-66

41. Jansson PA, Gudbjornsdottir HS, Andersson OK, Lonnroth PN (1996) The effect of metformin on adipose tissue metabolism and peripheral blood flow in subjects with NIDDM. Diabetes Care 19:160-164

42. Hallakou S, Doare L, Foufelle F et al (1997) Pioglitazone induces in vivo adipocyte differentiation in the obese Zucker fa/fa rat. Diabetes 46:1393-1399

43. Sripalakit P, Neamhom P, Saraphanchotiwitthaya A (2006) Highperformance liquid chromatographic method for the determination of pioglitazone in human plasma using ultraviolet detection and its application to a pharmacokinetic study. J Chromatogr B Analyt Technol Biomed Life Sci 843:164-169

44. Porta V, Schramm SG, Kano EK et al (2008) HPLC-UV determination of metformin in human plasma for application in pharmacokinetics and bioequivalence studies. J Pharm Biomed Anal 46:143-147

45. Watt MJ, Holmes AG, Pinnamaneni SK et al (2006) Regulation of HSL serine phosphorylation in skeletal muscle and adipose tissue. Am J Physiol Endocrinol Metab 290:E500-E508

46. Garton AJ, Campbell DG, Carling D, Hardie DG, Colbran RJ, Yeaman SJ (1989) Phosphorylation of bovine hormone-sensitive lipase by the AMP-activated protein kinase. A possible antilipolytic mechanism. Eur J Biochem 179:249-254

47. Egan JJ, Greenberg AS, Chang MK, Wek SA, Moos MC Jr, Londos C (1992) Mechanism of hormone-stimulated lipolysis in adipocytes: translocation of hormone-sensitive lipase to the lipid storage droplet. Proc Natl Acad Sci U S A 89:8537-8541

48. Su CL, Sztalryd C, Contreras JA, Holm C, Kimmel AR, Londos C (2003) Mutational analysis of the hormone-sensitive lipase translocation reaction in adipocytes. J Biol Chem 278:43615-43619

49. Issad $T$, Combettes M, Ferre $P$ (1995) Isoproterenol inhibits insulin-stimulated tyrosine phosphorylation of the insulin receptor without increasing its serine/threonine phosphorylation. Eur J Biochem 234:108-115

50. Kristensen JM, Johnsen AB, Birk JB et al (2007) Absence of humoral mediated 5'AMP-activated protein kinase activation in human skeletal muscle and adipose tissue during exercise. J Physiol 585:897-909 